\title{
TRB Annual Meeting
}

\section{Assessing Safety Performance on Urban and Suburban Roadways of Lower Functional Classification: A Comparison of Minor Arterial and Collector Roadway Segments

\author{
--Manuscript Draft--
}

\begin{tabular}{|c|c|}
\hline Full Title: & $\begin{array}{l}\text { Assessing Safety Performance on Urban and Suburban Roadways of Lower } \\
\text { Functional Classification: A Comparison of Minor Arterial and Collector Roadway } \\
\text { Segments }\end{array}$ \\
\hline Abstract: & $\begin{array}{l}\text { Previous research of urban roadway safety performance has generally focused on } \\
\text { roadways of high functional classifications, such as principal arterials. However, } \\
\text { roadways with lower functional classifications, including minor arterials and collectors, } \\
\text { typically possess characteristics that differ from those of higher roadway classes. } \\
\text { Therefore, assumptions made on the general effect of the predictor variables from } \\
\text { typical safety performance functions may not apply to lower roadway classes. To } \\
\text { address these knowledge gaps, a safety performance evaluation of urban/suburban } \\
\text { minor arterial and collector roadway segments was performed using traffic and } \\
\text { roadway data along with eight years of crash data from } 189 \text { miles of two-lane urban } \\
\text { and suburban roadways in Washtenaw County, Michigan. Mixed-effect negative } \\
\text { binomial models with segment-specific random intercept were developed for minor } \\
\text { arterial and collector road segments, considering total, fatal+injury, and property } \\
\text { damage only crashes. In general, minor arterial roadways showed greater crash } \\
\text { occurrence compared to collector roads. Posted speed limit had a significant positive } \\
\text { association with crash frequency, and this effect increased when the speed limit } \\
\text { exceeded } 40 \text { mph. The effect of speed limit was stronger on minor arterial segments } \\
\text { and for fatal+injury crashes. Additionally, driveway density was found to have } \\
\text { significant effect on safety performance, which was stronger for commercial/industrial } \\
\text { driveways compared to residential driveways and for collector roads compared to } \\
\text { minor arterials, particularly when considering residential driveways. On-street parking } \\
\text { was associated with lower crash occurrence, with a stronger effect on collector } \\
\text { roadways, likely due to greater parking turnover when compared to minor arterials. }\end{array}$ \\
\hline Manuscript Classifications: & $\begin{array}{l}\text { Infrastructure; Roadway Design; Low-Volume Roads AKD30; Safety; Performance } \\
\text { Effects of Geometric Design AKD10; Safety; Operations; Access Management ACP60; } \\
\text { Safety; Safety; Safety Performance and Analysis ACS20; Before and After Safety } \\
\text { Studies; Highway Safety Manual }\end{array}$ \\
\hline Manuscript Number: & TRBAM-22-01897 \\
\hline Article Type: & Presentation and Publication \\
\hline \multirow[t]{2}{*}{ Order of Authors: } & Meghna Chakraborty, MS \\
\hline & Timothy Jordan Gates, PhD \\
\hline \multicolumn{2}{|l|}{ Additional Information: } \\
\hline Question & Response \\
\hline $\begin{array}{l}\text { The total word count limit is } 7500 \text { words } \\
\text { including tables. Each table equals } 250 \\
\text { words and must be included in your count. } \\
\text { Papers exceeding the word limit may be } \\
\text { rejected. My word count is: }\end{array}$ & 7497 \\
\hline
\end{tabular}


1 Assessing Safety Performance on Urban and Suburban Roadways of Lower Functional

2 Classification: A Comparison of Minor Arterial and Collector Roadway Segments

3

4

\author{
Meghna Chakraborty \\ Graduate Research Assistant \\ Department of Civil and Environmental Engineering \\ Michigan State University \\ 428 S. Shaw Ln., East Lansing, MI 48824 \\ Email: chakra43@msu.edu \\ ORCID: https://orcid.org/0000-0002-8369-1198

\section{Timothy J. Gates (Corresponding Author)} \\ Associate Professor \\ Department of Civil and Environmental Engineering \\ Michigan State University \\ 428 South Shaw Lane, East Lansing, MI 48824 \\ Email: gatestim@msu.edu \\ ORCID: https://orcid.org/0000-0002-7429-0990
}

Word Count: $6,747+3$ tables $(250$ words per table $)=7,497$ words

Submitted for presentation and publication: July 31, 2021 


\section{Chakraborty and Gates}

\section{ABSTRACT}

2 Previous research of urban roadway safety performance has generally focused on roadways of high functional classifications, such as principal arterials. However, roadways with lower functional classifications, including minor arterials and collectors, typically possess characteristics that differ from those of higher roadway classes. Therefore, assumptions made on the general effect of the predictor variables from typical safety performance functions may not apply to lower roadway classes. To address these knowledge gaps, a safety performance evaluation of urban/suburban minor arterial and collector roadway segments was performed using traffic and roadway data along with eight years of crash data from 189 miles of two-lane urban and suburban roadways in Washtenaw County, Michigan. Mixed-effect negative binomial models with segment-specific random intercept were developed for minor arterial and collector road segments, considering total, fatal+injury, and property damage only crashes. In general, minor arterial roadways showed greater crash occurrence compared to collector roads. Posted speed limit had a significant positive association with crash frequency, and this effect increased when the speed limit exceeded $40 \mathrm{mph}$. The effect of speed limit was stronger on minor arterial segments and for fatal+injury crashes. Additionally, driveway density was found to have significant effect on safety performance, which was stronger for commercial/industrial driveways compared to residential driveways and for collector roads compared to minor arterials, particularly when considering residential driveways. On-street parking was associated with lower crash occurrence, with a stronger effect on collector roadways, likely due to greater parking turnover when compared to minor arterials.

21 Keywords: Urban/suburban roadways, minor arterials, collectors, two-lane segments, safety performance functions, roadway characteristics. 


\section{Chakraborty and Gates}

\section{INTRODUCTION}

2 The high economic and societal impacts associated with traffic crashes provides motivation for transportation agencies to proactively pursue traffic safety improvements (1). With the majority of the U.S population living in urban and suburban areas, urban roadways remain a critical aspect of roadway safety. Particularly, urban arterials and collectors, which typically possess speed limits of $50 \mathrm{mph}$ or lower, are an important part of the roadway system, and generally carry substantially high traffic volumes and provide more frequent access to roadside developments. Urban and suburban road segments account for approximately 30 percent of all road-miles both in the U.S (2) and Michigan (3). In 2019, urban roads in the U.S. experienced almost 70 percent of the total vehicle miles traveled (4) and majority of fatalities (55.4 percent) compared to rural roadways (5), a trend which has been sustained since 2016 (6). Also, as per the latest available data, the majority of urban fatal crashes (65 percent) in the U.S. occurred on roads where the speed limit was $50 \mathrm{mph}$ or lower (6). Moreover, urban areas accounted for majority of the pedestrian (79 percent) and bicyclist ( 75 percent) fatalities. More than half ( 55 percent) of alcohol-impaired drivers involved in traffic fatalities were driving in urban areas (6).

In Michigan, between 2009 and 2019, both total and fatal crashes have increased by 8.0 percent and 12.0 percent, respectively, with the increase in fatal crashes outpacing the increase nationwide, while the increase in vehicle miles traveled during this time was only about 6.5 percent. Similar to the latest nationwide statistics, urban fatal crashes have generally comprised the majority of crashes in Michigan. Moreover, non-intersection segment/midblock crashes have consistently accounted for over 65 percent of the total crashes statewide in Michigan (7).

Modeling crash risk in urban areas is generally more complicated than in rural areas due to the complexity of the driving environment and the difficulty obtaining data to fully characterize the road and surrounding environment. Urban areas contain a plethora of factors contributing to increased environmental complexity that are not captured by traditional data sources. Roadside development in urban areas is often much denser than in rural areas, bringing with it increased access points, parking areas (on-street and/or off-street), transit stops, and traffic signals, thereby increasing the complexity of the roadway environment.

\section{Roadway Functional Class and Traffic Safety}

Roadways in the U.S. have historically been classified functionally based on two primary criteria: land access and mobility. The significance of these two characteristics is different according to the road type, as indicated by the AASHTO Green Book, 2001 (8). In general, the mobility potential for a roadway decreases as access increases. AASHTO (9) specifies the three basic types of roadways, namely arterials, collector, and local roads/streets, based on traffic volumes, design characteristics, and method of financing. While arterials have high mobility level and they connect major trip generators which demand long trip length and high traffic volumes, collector roads collect traffic from lower category, connect local and arterial highways, and serve subordinate traffic generators. Lastly, local roads are characteristic of low volume public facilities, and their primary function is to provide access to adjacent land. Shortest distances, low speed and volume, lowest level of mobility and highest land access are the basic characteristics of these types of roads.

While understanding the impacts of the roadway and traffic environments on safety, one has to comprehend the functions and characteristics of different classes of roads. For non-freeway, non-major arterials roadways, this understanding in even more crucial. This is because, unlimited access directly from businesses and residences to roads of lower functional classes create a wide range of circumstances in the mix of access and movement functions and pose different kinds of safety concerns by creating more locations for potential conflicts of vehicular movements. The 


\section{Chakraborty and Gates}

1 proper "function" of any roadway is determined by consideration and evaluation of numerous complex factors including length of trips traveled on the road, speed of operation, degree of access control, degree of land service, freedom of movement, service to activity centers or traffic generators, system continuity, and traffic volume, among others.

\section{Problem and Objectives}

Previous research has generally focused on higher functional class roads, both in rural and urban areas $(10,11)$. The first edition of the Highway Safety Manual (HSM) includes separate families of safety performance functions (SPFs) to estimate annual crash occurrence for three specific roadway facility types: rural two-lane/two-way roads, rural multilane highways, and urban and suburban arterials (12). Separate SPFs exist for the base conditions within each facility type, while crash modification factors (CMFs) are provided to account for deviations from the base condition. Because the HSM SPFs were developed based on a limited sample of data collected from select states, direct application of the SPFs from the HSM does not tend to provide accurate results unless the models are calibrated using local data. Although local calibration of the HSM models is possible $(10,12-14)$, the fact remains that the SPFs in the HSM were generated based largely on data obtained from higher functional classes (i.e., primary arterials), which are typically owned by the state DOTs. Therefore, assumptions made on the general effect of the predictors, such as traffic volume or roadway characteristics, may not apply to lower urban/suburban roadway classes such as minor arterials and collectors, which are often owned by local agencies (e.g., city or county).

Furthermore, little is known about the influence of posted speed limit on the safety performance for such classes of road segments.

To address these knowledge gaps, a safety performance evaluation of urban/suburban minor arterial and collector roadway segments was performed. A series of safety performance functions were developed utilizing eight years of crash data (2011-2018), roadway characteristics, and traffic volume data, for two-lane undivided urban and suburban roadways with speed limits between 25 mph to $50 \mathrm{mph}$ from the Washtenaw County (i.e., greater Ann Arbor), Michigan. The findings from this evaluation are timely and relevant given the apparent lack of documentation on the safety performance of urban minor arterials and collectors, including the influence of posted speed limit.

\section{LITERATURE REVIEW}

Prior research has explored the safety effects of various roadway geometric factors for urban roadways. The following subsections summarize the extant literature regarding the relationship between the primary characteristics of urban roads and safety performance.

\section{Posted Speed Limit}

Prior evaluations have suggested that increases in crashes due to increased operating speeds and/or speed limits are more pronounced in urban areas, where traffic congestion is much higher compared to rural areas $(15,16)$. An early study that analyzed crashes from 21 countries for both rural and urban regions showed that speed limits in urban areas, in particular, have a considerable effect on safety (17). Taylor et al. reported that reducing the speed of the fastest drivers brings greater safety benefits than reducing the overall average speed of all drivers, especially on urban roads (16). In another study for urban state highways, findings indicate that the likelihood of a fatal crash increases from 0.7 percent at $25 \mathrm{mph}$ to 3.7 percent at $70 \mathrm{mph}$ (18). Some studies, however, presented conflicting results on the safety effects of posted speed limits. A study from Washington estimated the non-intersection crash rates of urban four-lane undivided roads and found four-lane 


\section{Chakraborty and Gates}

1 undivided roads with speed limits of $30 \mathrm{mph}$ and $45 \mathrm{mph}$ to have more crashes than those with 35 $\mathrm{mph}$ and $40 \mathrm{mph}$ (19). Another study on the safety of urban and suburban arterials in Minnesota considered three speed limit categories: low (30 mph or less); intermediate (35 to $45 \mathrm{mph}$ ); and high (50 mph or more). In almost all cases, higher crash occurrence was observed on lower speed arterials, which was thought to be caused by greater traffic flow turbulence resulting from the greater density of driveways on these segments (20).

\section{Driveway Density}

Prior research indicates a relationship between increased driveway or access density and increased crash occurrence $(10,12,21,22,14)$. A study by Papayannoulis et al. (1999) suggested that increasing the access frequency from 10 to 20 access points per mile would increase crash rates by 40 percent while increasing to 60 access points per mile would triple the crash rate as compared with 10 access points per mile. It was estimated that each additional access point increases the crash rate by about 4 percent (23). McLean (1997) suggested that each additional private driveway per kilometer would increase the crash rate by about 1.5 percent and 2.5 percent for two-lane and four-lane roads, respectively (15).

The utilization of driveways obviously influences the impact on safety performance. Dixon et al. (2012) developed SPFs to evaluate the safety impacts of various driveway types on rural and urban arterial state highways in Oregon. Different effects were observed for urban and rural conditions, but land use type was found to be a key factor for both urban and rural area with commercial and industrial driveways being associated with greater crash occurrence in urban environment (21). In urban areas, it has been estimated that commercial driveways increase crash rates by approximately 5 times that of private residential driveways due to the greater utilization (15). A study by Hauer et al. (2004) revealed a significant relationship between non-intersection crashes and traffic volume, the number of commercial driveways, and speed limits on urban fourlane undivided roads (19).

\section{Roadway Cross-Sectional Features}

Various roadway cross-sectional features are known to influence crash occurrence. In terms of lane width, mixed results have been found in prior safety performance evaluations. Potts et al. (2007) determined that greater lane width was associated with a higher occurrence of property damage only (PDO) crashes on urban four-lane undivided roads, although no relationship was found between lane with and the occurrence of run-off-road crashes (24). Hadi et al. (1995) found that increasing lane widths up to $12 \mathrm{ft}$ and $13 \mathrm{ft}$ was likely to decrease crash rates for urban two-lane and four-lane undivided roadways, respectively (25). Another study showed that as lane width decreased, speeds decreased, and crashes increased on four-lane undivided urban arterial segments (26). Milton and Mannering (1998) concluded that, narrower "substandard" lane widths (<11.5 ft) reduce crash frequency (27). Collectively, the prior literature suggests that the relationship between crash occurrence and safety performance is difficult to estimate, and likely does not follow a monotonic relationship.

Horizontal curves are a necessary part of the highway system, although they are widely known to pose significant safety concerns due to the changes in driver expectancy and vehicle maneuvers. Prior research has indicated that traffic crashes occur more frequently and are more severe on horizontal curves compared to straight segments $(28,29)$, and fatal crash rates are three times greater on horizontal curves than straight segments (30). While most evaluations of curvature have focused on rural roadways, urban residential collector road segments have been found to possess a significant positive relationship between the presence of a horizontal curve and crash 


\section{Chakraborty and Gates}

occurrence (31). Hauer et al. (2004) found a strong relationship between the degree horizontal curvature and run-off-road crashes on urban four-lane undivided segments (19). Another recent study showed that the horizontal curvature has significant safety effect on two-lane undivided urban arterials with speed limits of $35 \mathrm{mph}$ and higher (32).

Turning to other roadway cross-sectional features, a study by Fitzpatrick (2003) suggested that several factors other than posted speed limit influence safety and operating speed on tangent roadway sections, including access density, median type, and parking along the streets, among others (33). Hauer et al. (2004) determined that on-street parking results in slightly fewer crashes compared to roadways where parking is prohibited (19). Conversely, Greibe (2003) found roads with on-street parking have greater crash risk, particularly for crashes involving pedestrians and parked vehicles, and involving motor vehicles from minor roads (34). Zegeer et al. (2001) suggested that on two-lane roads and lower volume multilane roads, crosswalks alone, without other traffic calming treatments, are not recommended to be installed at uncontrolled locations or locations that may pose unusual safety risks to pedestrians (35).

To summarize, considerable research has been conducted to understand the safety performance of urban arterials in general, but little research has explored urban minor arterial or collector road segments with lower speed limits. An important aspect of urban roads of lower functional classes is the high degree of connectivity to roadside development, creating a complex interaction with roadway cross-sectional elements and speed limit. This research seeks to fill these knowledge gaps utilizing data for urban and suburban two-lane undivided roadways in Washtenaw County, Michigan, which collective possessed a broad range of traffic volumes, cross-sectional characteristics, and speed limits.

\section{METHODOLOGY Data Collection}

Prior to developing the safety performance functions, it was first necessary to collect and integrate data on traffic crashes, traffic volumes, and roadway characteristics. The geospatial analysis was performed in the ESRI's ArcGIS platform using existing shapefiles, where available, while additional data were added manually. The geographic boundary for the data analyzed was Washtenaw County, which is located in the Southeast Michigan. Washtenaw County is the sixth largest county in the State of Michigan with a population of 344,791, as per the latest available census data (36). Within Washtenaw County's 721 square miles are 29 local units of government including seven cities, six charter townships, fourteen civil townships, and two villages, thereby providing a diverse collection of urban and suburban roadway networks and land use contexts. The County comprises the Ann Arbor Metropolitan Statistical Area and is included in the DetroitWarren-Ann Arbor Combined Statistical Area.

\section{Roadway Segment Data}

Initially, the roadway inventory data for all public highways in Washtenaw County was collected via the Michigan Geographic Framework (MGF) "All Roads" version 17 shapefile from the Michigan Center for Geographic Information (MCGI) open data portal (37). The MGF "All Roads" file consists of all public road segments along with the census boundaries and other spatial characteristics across the state. Posted speed limits from the SEMCOG database were also joined with the roadway data. This data was integrated based on the physical road (PR) reference number (based on a statewide linear referencing system), begin milepoints (BMP), end milepoints (EMP) of the segments. The candidate roadways in this study were segmented in a way such that each 


\section{Chakraborty and Gates}

1 roadway segment's endpoints were intersections controlled via either signalization, stop control (on the subject roadway), a roundabout, or the route otherwise ending (such as the county line). A spatial analysis was performed on ArcGIS to identify the location of all public roadway intersections along these roadways. A manual review of satellite imagery was undertaken to determine the traffic control for each intersection. This data was further reduced to only include urban and suburban roadways that had posted speed limits ranging from $25 \mathrm{mph}$ to $50 \mathrm{mph}$. Ultimately, the study segments included two-lane undivided roadways that were classified as minor arterial or collector, while excluding freeways, major arterials, and local roads. A minimum segment length of 0.1 miles was selected for this analysis as recommended by HSM (12). Figure 1 shows the two-lane undivided segments included in this analysis.

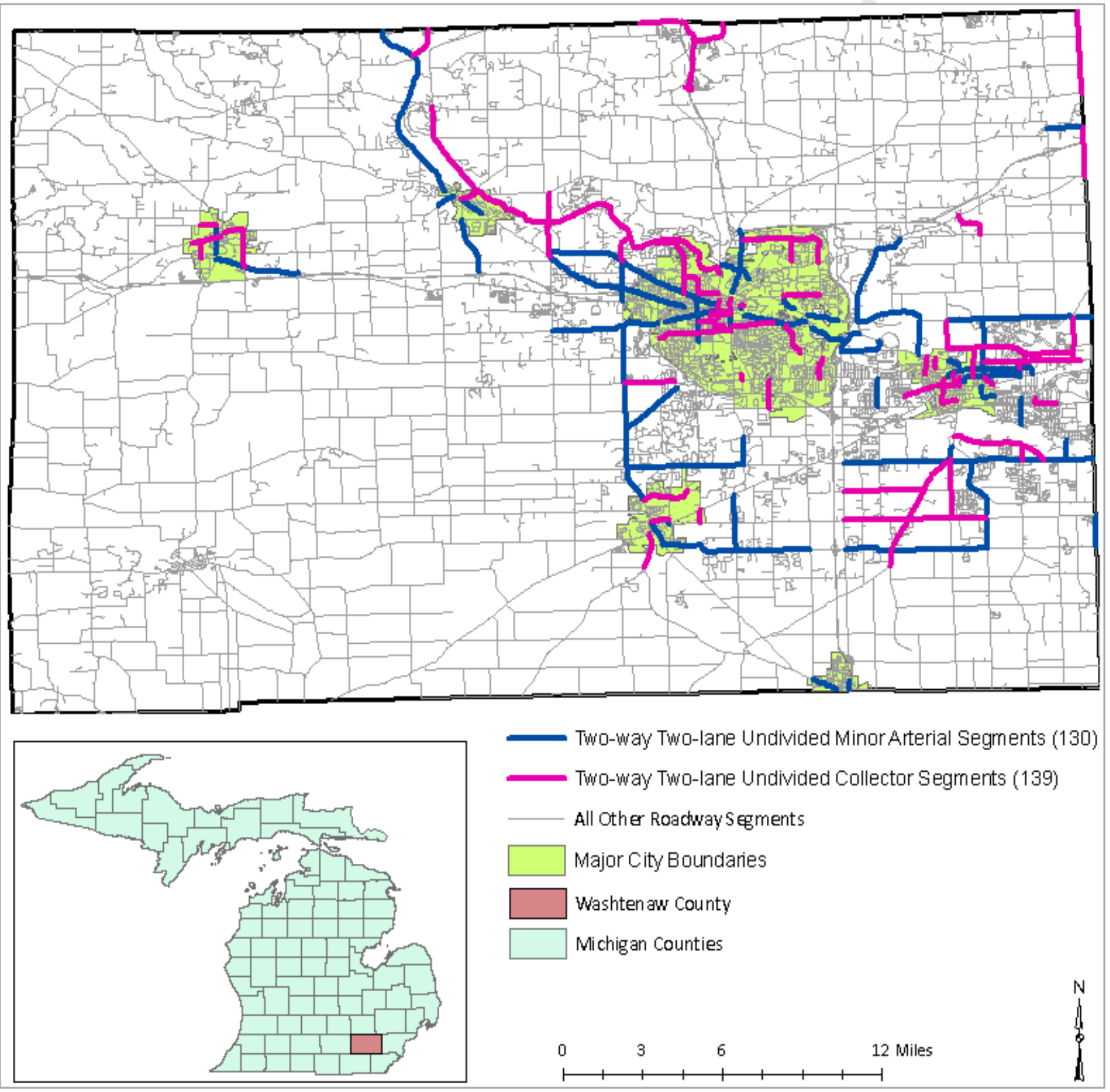

Figure 1 Two-lane two-way undivided minor arterial and collector roadway study segments in Washtenaw County, Michigan. 
Chakraborty and Gates

\section{Traffic Volumes}

AADT volume estimates were obtained from the Federal Highway Administration's (FHWA) Highway Performance Monitoring System (HPMS) (38) shapefile and the Southeast Michigan Council of Governments (SEMCOG) (39) open-source database. These AADTs were then spatially matched to the appropriate segment in the roadway data based on linear referencing. In all cases, these traffic volume data represent actual observed counts along the road segments. Annual traffic growth factors were obtained from Washtenaw County and applied to the traffic volumes to adjust to the appropriate analysis year, where necessary.

\section{Crash Data}

The historical traffic crash data were collected from the annual statewide crash database Traffic Crash Reporting System (TCRS), maintained by MDOT. For this study, crash data for an eightyear period from 2011 to 2018 were utilized. Crashes on each segment were included, excluding those occurring within $250 \mathrm{ft}$ of the terminal intersections on either end. The crash data, along with all relevant information including crash severity and type, were aggregated annually and merged with the roadway data for each segment. Furthermore, contrasting with prior analyses in urban areas, the analysis was not limited to multi-vehicle crashes only, and single vehicle run-off-road crashes were included. This is primarily due to small crash sample sizes and the potential for runoff-road crashes on higher speed roadways to occur because of the influence of other vehicles entering the roadway.

\section{Other Data}

Additional data were manually reviewed in Google Earth and subsequently joined with the roadway data for each segment. This additional data included:

- count and classification of access points (residential driveway, commercial driveway, public intersections)

- presence of bus stops, school zones, sidewalks, crosswalks, bike lanes, on-street parking, and midblock crosswalks;

- widths of travel lanes, shoulders, bike lanes, parking lanes, and the space between sidewalks and traffic lanes; and

\section{Data Summary and Preliminary Analysis}

In total, 188.5 miles of two-lane undivided urban/suburban roadways, consisting of 269 segments were included in this study. Approximately, 48 percent of these study segments were minor arterials, while with the remaining 52 percent were collector road segments including both major and minor collectors. The segment summary statistics associated with these segments are presented in Table 1. As can be seen from Table 1, not surprisingly, traffic volume is considerably higher on minor arterials compared to that on collector roads, while the average segment length is also slightly greater on minor arterials. Consistent with the higher functional classification, minor arterials have a higher average posted speed limit with respect to the collector roadway counterparts. Also as expected, the average driveway density is greater on collectors for all land use types. While the average lane width is comparable between minor arterial and collector road segments, the presence of on-street parking in substantially more prevalent on the collector segments. Also, on-street parking, midblock crosswalks, horizontal curvatures, bus stops, and sidewalks are more prevalent on collector road segments, consistent with the urban nature of lower class of road segments. Lastly, for all severities of midblock crashes analyzed, average annual 


\section{Chakraborty and Gates}

1 crash frequency per mile is consistently higher on minor arterials compared to that on collector road

2 segments.

TABLE 1 Two-Lane Two-Way Undivided Road Segment Descriptive Statistics

\begin{tabular}{|c|c|c|c|c|c|}
\hline Parameter & Level or Unit & Min & Max & Mean & Std Dev \\
\hline \multicolumn{6}{|c|}{ Two Lane Two-Way Undivided Minor Arterial Segments $(n=130)$} \\
\hline AADT & vehicles/day & 856 & 20,710 & $8,352.1$ & $3,898.3$ \\
\hline Segment Length & miles & 0.1 & 3.58 & 0.77 & 0.7 \\
\hline Posted Speed Limit & miles/hour & 25 & 50 & 37.92 & 9.30 \\
\hline Total Driveway Density & count/mile & 0 & 107.28 & 36.04 & 29.68 \\
\hline Residential Driveway Density & count/mile & 0 & 107.28 & 29.68 & 28.95 \\
\hline Commercial Driveway Density & count/mile & 0 & 46.88 & 6.36 & 8.39 \\
\hline Lane Width & & 10 & 14 & 11.13 & 0.65 \\
\hline On-street Parking Presence & & 0 & 1 & 0.15 & 0.36 \\
\hline Crosswalk Presence & & 0 & 1 & 0.15 & 0.42 \\
\hline Horizontal Curve Presence & & 0 & 1 & 0.15 & 0.35 \\
\hline Bike Lane Presence & & 0 & 1 & 0.19 & 0.39 \\
\hline Sidewalk Presence & & 0 & 1 & 0.65 & 0.48 \\
\hline Bus Stop Presence & & 0 & 1 & 0.22 & 0.41 \\
\hline School Zone Presence & & 0 & 1 & 0.06 & 0.24 \\
\hline All Segment Crashes & count/year/mile & 0 & 41.24 & 5.38 & 5.85 \\
\hline Fatal and Injury Segment Crashes & count/year/mile & 0 & 17.09 & 1.12 & 1.90 \\
\hline PDO Segment Crashes & count/year/mile & 0 & 41.24 & 4.26 & 5.04 \\
\hline \multicolumn{6}{|c|}{ Two Lane Two-Way Undivided Collector Segments $(n=139)$} \\
\hline AADT & vehicles/day & 380 & 13,395 & $5,041.7$ & $3,128.1$ \\
\hline Segment Length & miles & 0.1 & 6.84 & 0.65 & 0.86 \\
\hline Posted Speed Limit & miles/hour & 25 & 50 & 30.94 & 7.72 \\
\hline Total Driveway Density & count/mile & 0 & 123.02 & 40.82 & 32.27 \\
\hline Residential Driveway Density & count/mile & 0 & 123.02 & 32.41 & 32.53 \\
\hline Commercial Driveway Density & count/mile & 0 & 60.98 & 8.41 & 10.96 \\
\hline Lane Width $>11$ feet & & 10 & 15 & 11.40 & 1.13 \\
\hline On-street Parking Presence & & 0 & 1 & 0.34 & 0.47 \\
\hline Crosswalk Presence & & 0 & 1 & 0.19 & 0.39 \\
\hline Horizontal Curve Presence & & 0 & 1 & 0.22 & 0.42 \\
\hline Bike Lane Presence & & 0 & 1 & 0.15 & 0.36 \\
\hline Sidewalk Presence & & 0 & 1 & 0.79 & 0.41 \\
\hline Bus Stop Presence & & 0 & 1 & 0.30 & 0.46 \\
\hline School Zone Presence & & 0 & 1 & 0.05 & 0.22 \\
\hline All Segment Crashes & count/year/mile & 0 & 38.31 & 3.06 & 4.74 \\
\hline Fatal and Injury Segment Crashes & count/year/mile & 0 & 15.63 & 0.56 & 1.54 \\
\hline PDO Segment Crashes & count/year/mile & 0 & 36.23 & 2.51 & 4.13 \\
\hline
\end{tabular}


Chakraborty and Gates

$1 \quad$ Mixed Effects Negative Binomial Regression Models

2 Traditional linear regression techniques are generally inappropriate as crash data comprise non-

3 negative integers. As an alternative, the Poisson distribution provides a starting point for the analyses. In Poisson model, the probability of segment $i$ experiencing $y_{i}$ crashes in one year can be expressed as

$$
P\left(y_{i}\right)=\frac{\exp \left(-\lambda_{i}\right) \lambda_{i} y_{i}}{y_{i} !}
$$

where $\mathrm{P}\left(y_{i}\right)$ is the probability of segment $i$ experiencing $y_{i}$ crashes, and $\lambda_{i}$ is the Poisson parameter or the expected number of annual crashes for segment $i$, $\mathrm{E}\left[y_{i}\right]$.

The Poisson regression model relates the expected number of crashes on a segment, $\lambda_{i}$, to a function of explanatory variables, expressed as

$$
\lambda_{i}=\exp \left(\beta X_{i}\right)
$$

where $X_{i}$ is a vector of explanatory variables and $\beta$ is a vector of estimable parameters.

A limitation with Poisson distribution is the assumption that the mean and variance are equal, which often is not the case with crash data. Commonly with crashes, variance exceeds mean, leading to an overdispersion. The negative binomial model addresses this overdispersion by adding an unobserved heterogeneity term as,

$$
\lambda_{i}=\exp \left(\beta X_{i}+\varepsilon_{i}\right)
$$

where $\exp \left(\varepsilon_{i}\right)$ is a gamma-distributed error term with mean 1 and variance $\alpha$.

The inclusion of this term essentially allows the variance to differ from mean as

$$
\operatorname{VAR}\left[y_{i}\right]=E\left[y_{i}\right]+\alpha E\left[y_{i}\right]^{2}
$$

This $\alpha$ is termed as the overdispersion parameter. In the safety impact analysis, negative binomial regression models have been widely used (40-42) and accepted as the current practice for modeling crashes, as such models account for overdispersion.

Recently, random effects negative binomial models have become popular due to the capability of accounting for spatial effects and heterogeneity across observations $(43,44)$. Unobserved heterogeneity can be defined as unknown variability in the effect of variables across the sample population. If this issue is not taken into account and the effects of observable variables are held the same across all observations, predictions might be erroneous resulting from the biased estimated parameters (45). To address the issues with non-random sampling and unobserved heterogeneity in the data, segment-specific random parameter (intercept) was included in the negative binomial models, effectively developing mixed-effects models. In a mixed-effects model, each intercept is drawn at random from the intercept distribution and is independent of the error term for any particular observation and uncorrelated with the independent variables. The regression analysis in this study was conducted using R Studio.

\section{RESULTS AND DISCUSSION}

Tables 2 and 3 display the results of mixed-effect negative binomial models that were separately developed for minor arterials and collector roads, respectively. Additionally, separate models were estimated for total, fatal and injury (FI), and PDO crashes. In all models, AADT is included in natural log form and the elasticity of the parameter estimate can, thus, be interpreted directly. The coefficient for the natural log of the segment length was set to 1 (i.e., the length is treated as an offset), which normalizes the crash counts per unit length as the crash frequency on a segment is generally considered to be proportional to the segment length. Several combinations of independent variables were tested during model development, with the final form of the models 


\section{Chakraborty and Gates}

1 selected based on assessment of the p-values, AIC, and log-likelihood information. Variables that

\section{Minor Arterial Road Segments}

The results of the analysis of minor arterial segments revealed several interesting findings. First, the relationship between traffic crash frequency and AADT is non-linear and inelastic, a finding consistent with prior research $(46,47)$. With regard to the effects of posted speed limits, crash occurrence consistently increased with increasing speed limit, which is consistent with previous research on urban road segments $(16,47)$. While this trend was observed for both PDO and FI crashes, the effect was larger for FI crashes. Specifically, the parameter estimates indicate 5.5 percent, 9.0 percent, and 3.5 percent greater total, FI, and PDO crashes, respectively, on segments with posted speed limit of 35 to $40 \mathrm{mph}$, compared to segments with 25 to $30 \mathrm{mph}$ speed limit. The parameter estimates increase further when the speed limit is greater than $40 \mathrm{mph}$, indicating 7.4 percent, 12.0 percent, and 7.6 percent greater crash occurrence for total, FI, and PDO crashes, respectively, compared to segments with 25 to $30 \mathrm{mph}$ speed limit.

Turning to the safety effects of driveway density across the various driveway land use categories, the density of both residential and commercial/industrial driveway types was found to be positively associated with crash frequency (i.e., greater driveway density results in higher crash occurrence), and this effect is greater for PDO compared to FI crashes. Considering driveway landuse type, commercial/industrial driveways were found to have a stronger effect on crashes than residential driveways across all severity levels, likely due to greater utilization. The parameter estimates indicate that crash occurrence increases by 1.4 percent, 0.9 percent, and 1.5 percent for total, FI, and PDO crashes, respectively, with every one additional residential driveway per mile segment. Similarly, the crash occurrence increases by 5.1 percent, 4.7 percent, and 5.4 percent for total, FI, and PDO crashes, respectively, with every one additional commercial or industrial driveway per mile segment. These results suggest that commercial/industrial driveways increase crash occurrence at rates that are 3.6 times and 5.2 times greater than residential driveways for PDO and FI crashes, respectively. Overall, these results are aligned with prior research that found crash frequency on urban roads to increase with increasing driveway density, and that commercial driveways have more pronounced effect on crash occurrence compared to residential driveways (19, $21,22)$. Furthermore, the finding that traffic volume, driveway density, and posted speed limit in interaction with each another, influence safety significantly on urban roadways compares favorably with a prior study by Hauer et al. (2004) where the model fits depended mostly on variables including AADT, number of commercial driveways, and speed limit (19).

Turning to the effects of other roadway factors, on-street parking is found to increase crash likelihood for total and PDO crashes, and reduce crash frequency for FI crashes on minor arterial segments. This is not a surprising result, as on-street parking, while introducing additional vehicleto-vehicle conflicts, also tends to reduce operating speeds, thereby reducing the likelihood of FI crashes. Additionally, while the presence of a horizontal curvature, midblock crosswalks, and bus stops are associated with increased crash occurrence, school zone presence and lane width greater than 11 feet are found to decrease crash likelihood on minor arterial roadways. Presence of school zones show a stronger negative association with FI crashes, perhaps due to drivers traversing school zones more cautiously and at lower rates of speed than along comparable segments in other areas. Interestingly, presence of sidewalks demonstrates a counterintuitive positive association with PDO crashes only, perhaps due to the increased parking and/or pedestrian activity on these. 
Chakraborty and Gates

1 TABLE 2 Mixed Effects Negative Binomial Model Results for Urban/Suburban Minor Arterial Road

2 Segments

\begin{tabular}{|c|c|c|c|c|c|c|c|c|c|}
\hline & \multicolumn{3}{|c|}{ Total Crashes } & \multicolumn{3}{|c|}{ Fatal and Injury Crashes } & \multicolumn{3}{|c|}{$\begin{array}{l}\text { Property Damage Only } \\
\text { Crashes }\end{array}$} \\
\hline & Est. & SE & p-value & Est. & SE & p-value & Est. & SE & $\begin{array}{l}p- \\
\text { value }\end{array}$ \\
\hline Intercept & -3.925 & 1.037 & $<0.001$ & -5.463 & 1.262 & $<0.001$ & -4.040 & 1.067 & $<0.001$ \\
\hline Ln(AADT) & 0.608 & 0.115 & $<0.001$ & 0.606 & 0.139 & $<0.001$ & 0.593 & 0.118 & $<0.001$ \\
\hline Speed Limit 25 to $30 \mathrm{mph}$ & \multicolumn{3}{|c|}{ Baseline } & \multicolumn{3}{|c|}{ Baseline } & \multicolumn{3}{|c|}{ Baseline } \\
\hline Speed Limit 35 to $40 \mathrm{mph}$ & 0.053 & 0.184 & 0.077 & 0.086 & 0.221 & 0.070 & 0.034 & 0.187 & 0.086 \\
\hline Speed Limit 45 to $50 \mathrm{mph}$ & 0.071 & 0.191 & 0.071 & 0.114 & 0.224 & 0.061 & 0.073 & 0.194 & 0.071 \\
\hline Residential Driveway Density & 0.014 & 0.002 & 0.057 & 0.009 & 0.003 & 0.076 & 0.015 & 0.003 & 0.055 \\
\hline Commercial Driveway Density & 0.050 & 0.010 & 0.040 & 0.046 & 0.013 & 0.055 & 0.053 & 0.010 & 0.041 \\
\hline No On-street Parking & \multicolumn{3}{|c|}{ Baseline } & \multicolumn{2}{|c|}{ Baseline } & & \multicolumn{3}{|c|}{ Baseline } \\
\hline On-street Parking Present & 0.020 & 0.197 & 0.092 & -0.347 & 0.258 & 0.018 & 0.115 & 0.201 & 0.057 \\
\hline No Midblock Crosswalk & \multicolumn{3}{|c|}{ Baseline } & \multicolumn{2}{|c|}{ Baseline } & & \multicolumn{3}{|c|}{ Baseline } \\
\hline Midblock Crosswalk Present & 0.262 & 0.167 & 0.012 & 0.123 & 0.190 & 0.052 & 0.278 & 0.169 & 0.010 \\
\hline No Bus Stop & \multicolumn{3}{|c|}{ Baseline } & \multicolumn{2}{|c|}{ Baseline } & & \multicolumn{3}{|c|}{ Baseline } \\
\hline Bus Stop Present & 0.185 & 0.157 & 0.024 & 0.147 & 0.179 & 0.041 & 0.212 & 0.159 & 0.018 \\
\hline No School Zone & \multicolumn{3}{|c|}{ Baseline } & \multicolumn{3}{|c|}{ Baseline } & \multicolumn{3}{|c|}{ Baseline } \\
\hline School Zone Present & -0.022 & 0.225 & 0.092 & -0.072 & 0.236 & 0.076 & -0.037 & 0.226 & 0.087 \\
\hline Lane Width $\leq 11$ feet & \multicolumn{3}{|c|}{ Baseline } & \multicolumn{3}{|c|}{ Baseline } & \multicolumn{3}{|c|}{ Baseline } \\
\hline Lane Width > 11 feet & -0.290 & 0.180 & 0.011 & -0.255 & 0.215 & 0.024 & -0.285 & 0.184 & 0.012 \\
\hline No Horizontal Curvature & \multicolumn{3}{|c|}{ Baseline } & \multicolumn{3}{|c|}{ Baseline } & \multicolumn{3}{|c|}{ Baseline } \\
\hline Horizontal Curvature Present & 0.203 & 0.160 & 0.021 & 0.158 & 0.171 & 0.035 & 0.212 & 0.161 & 0.019 \\
\hline No Sidewalk & \multicolumn{3}{|c|}{ Baseline } & \multicolumn{3}{|c|}{ Baseline } & \multicolumn{3}{|c|}{ Baseline } \\
\hline Sidewalk Present & 0.109 & 0.148 & 0.162 & 0.238 & 0.154 & 0.123 & 0.089 & 0.149 & 0.055 \\
\hline Overdispersion & \multicolumn{3}{|c|}{0.031} & \multicolumn{3}{|l|}{0.079} & \multicolumn{3}{|l|}{0.032} \\
\hline Log-likelihood & \multicolumn{3}{|c|}{-1995.5} & -1112 & & & -1846.6 & & \\
\hline AIC & 4019.1 & & & 2252.9 & & & 3721.2 & & \\
\hline
\end{tabular}

\section{Collector Road Segments}

As can be seen from Table 3, the relationship between traffic crash frequency and AADT for collector roadways is less elastic than that for minor arterials. Similar to the minor arterial road segments, significant adverse safety impacts were associated with an increasing speed limit with greater effect on FI crashes. However, the relationship between posted speed limit and crash occurrence was weaker for collector roads compared to minor arterials. Specifically, the parameter estimates indicate 1.8 percent, 2.0 percent, and 1.8 percent greater total, FI, and PDO crashes, respectively, on segments with posted speed limit of 35 to $40 \mathrm{mph}$, compared to segments with 25 to $30 \mathrm{mph}$ speed limit. Similar to the minor arterials, the parameter estimates increased incrementally when the speed limit is greater than $40 \mathrm{mph}$, indicating 2.9 percent, 6.1 percent, and 2.0 percent greater crash occurrence for total, FI, and PDO crashes, respectively, compared to segments with 25 to $30 \mathrm{mph}$ speed limit. 


\section{Chakraborty and Gates}

Both residential and commercial/industrial driveway densities were associated with increased crash occurrence, and the effect of this factor was stronger on collector roads compared to minor arterials, especially when considering residential driveways. Similar to minor arterials, commercial/industrial driveways have stronger effect on crashes for all crash severities than do residential driveways. Particularly, the parameter estimates indicate that crash occurrence increases by 3.7 percent, 2.4 percent, and 3.5 percent for total, FI, and PDO crashes, respectively, with every one additional residential driveway per mile segment. Similarly, crash occurrence increases by 5.4 percent, 6.6 percent, and 5.5 percent for total, FI, and PDO crashes, respectively, with every one additional commercial/industrial driveway per mile segment. Further, the effect of residential driveway density is greater for PDO crashes, although, interestingly, the commercial/industrial driveway density effect is greater for FI crashes than PDO.

Additionally, unlike minor arterials, on-street parking is found to decrease crash likelihood on collector roads across all severity levels, which was consistent with prior research (19). Midblock crosswalks were found to be associated with increased crash likelihood, and this effect is stronger on collector roads compared to minor arterials. Bus stop presence is associated with greater crash frequency for total and FI crashes, and unlike minor arterials, the presence of a horizontal curvature and school zones did not have any significant impact on crashes. For horizontal curves, this result is likely due to underdesigned horizontal curves being relatively uncommon on urban/suburban collector segments. (i.e. curves that are designed below the speed limits). Lane width greater than 11 feet was associated with a decreased occurrence of PDO crashes only. Unlike minor arterials, presence of sidewalks on collector segments was found to be negatively associated with FI crash occurrence, but with no discernable impact on PDO crashes. 
Chakraborty and Gates

1 TABLE 3 Mixed Effects Negative Binomial Model Results for Urban/Suburban Collector Road

2 Segments

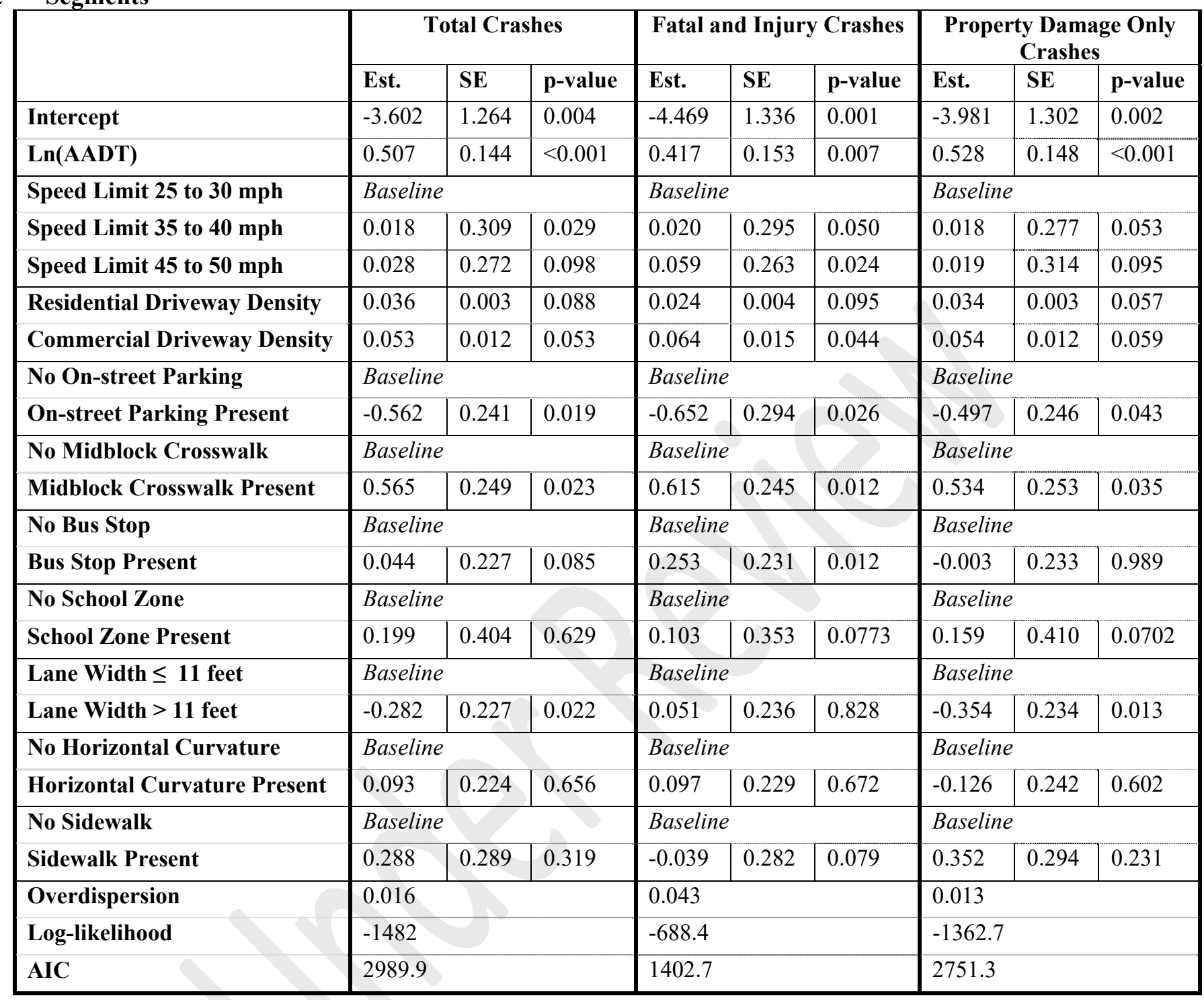

\section{SUMMARY AND CONCLUSIONS}

Previous research of roadway safety performance has generally focused on higher functional class roadways, both in rural and urban areas. However, roadways with lower functional classifications typically possess traffic, driver, design, and maintenance characteristics that differ from those of higher classes. Therefore, assumptions made on the general effect of the predictor variables from typical safety performance functions, such as traffic volume or roadway characteristics, may not apply to lower urban/suburban roadway classes such as minor arterials and collectors, which are often owned by local agencies. Lower class urban/suburban roads collectively present a broad range of roadway and traffic conditions, including speed limits, land access, pedestrian/bicyclist activity, transit activity, and parking, leading to complex interactions between road users.

To address these knowledge gaps, a safety performance evaluation of urban/suburban minor arterial and collector roadway segments was performed. A series of safety performance functions were developed utilizing eight years of crash data (2011-2018), roadway characteristics, and traffic 


\section{Chakraborty and Gates}

volume data, for approximately 189 miles of two-lane undivided urban and suburban roadways with speed limits between $25 \mathrm{mph}$ to $50 \mathrm{mph}$ from Washtenaw County (i.e., greater Ann Arbor), Michigan. Mixed-effect negative binomial models with segment-specific random intercept were developed separately for minor arterial and collector road segments, and for total, FI, and PDO crashes.

In general, minor arterial roadways showed greater crash occurrence compared to collector roads. Posted speed limit was found to have a significant positive association with crash frequency, and this effect increased when the speed limit exceeds $40 \mathrm{mph}$. This effect was stronger on minor arterial segments and was also stronger when considering FI crashes compared to PDO crashes.

Additionally, driveway density was found to have significant effect on safety performance across all driveway land use types both for minor arterials and collectors. Not surprisingly, commercial/industrial driveways were found to have a stronger effect on crash frequency than residential driveways, likely due to greater utilization. Moreover, the impact of driveway density was stronger on collector roads compared to minor arterials, particularly when considering the effect of residential driveways. In general, driveways possessed a greater effect on PDO crashes than FI crashes, although when considering commercial/industrial driveways on collector segments, the effect was stronger for FI crashes.

Lane width greater than 11 feet generally showed reduced crash occurrence across both segment types. Midblock crosswalks and bus stops were associated with increased crash occurrence. On-street parking was generally associated with lower crash occurrence, with a stronger effect occurring on collectors compared to minor arterials, likely due to greater turnover. Lastly, on minor arterials, school zone presence was associated with lower crash occurrence, while horizontal curves were associated with elevated crash occurrence.

Overall, the results of this study support the previous research findings and provides further evidence that roadway characteristics impact safety to different extents across different functional classifications. Most importantly, this study contributes to the limited body of knowledge regarding the safety performance characteristics observed on lower functional classes of urban/suburban roads, specifically minor arterials and collectors, which typically possess design and travel characteristics that are considerably different from those of primary arterials.

This study also recognizes some limitations and provides scope for future research in order to further refine and broaden the scope of the safety performance models for lower class urban/suburban roadways presented here. It would be insightful to further analyze the types of crashes occurring on these urban/urban roadway classes, particularly those involving vulnerable road users, which was not performed herein due to the very small sample sizes. Also, to account for regional diversity across larger geographic boundaries, the inclusion of additional data from other urban/suburban regions is recommended.

\section{ACKNOWLEDGMENTS}

Analysis of this research used the data primarily collected for a project funded by the National Cooperative Highway Research Program (NCHRP) program. This publication is disseminated in the interest of information exchange.

\section{AUTHOR CONTRIBUTIONS}

The authors confirm contribution to the paper as follows: study conception and design: Meghna Chakraborty; data collection: Meghna Chakraborty; analysis and interpretation of results: Meghna Chakraborty, draft manuscript preparation: Meghna Chakraborty, Timothy Gates. All authors reviewed the results and approved the final version of the manuscript. 
Chakraborty and Gates

\section{REFERENCES}

2 1. Blincoe, L., T. R. Miller, E. Zaloshnja, and B. A. Lawrence. The Economic and Societal Impact of Motor Vehicle Crashes, 2010. Annals of Emergency Medicine, Vol. 66, No. 2, 2015, pp. 194-196.

2. Table HM-12 - Highway Statistics 2016 - Policy | Federal Highway Administration. https://www.fhwa.dot.gov/policyinformation/statistics/2016/hm12.cfm. Accessed Apr. 23, 2019.

3. Table HM-10 - Highway Statistics 2016 - Policy | Federal Highway Administration. https://www.fhwa.dot.gov/policyinformation/statistics/2016/hm10.cfm. Accessed Apr. 23, 2019.

4. Highway Statistics 2019. Annual Vehicle Distance Traveled in Miles and Related Data 2019(1) by Highway Category and Vehicle Type. Table VM-1.

5. FARS Encyclopedia. https://www-fars.nhtsa.dot.gov/Main/index.aspx. Accessed May 20, 2019.

6. Traffic Safety Facts, 2018 Data. Rural/Urban Comparison. Publication DOT HS 812957. National Center for Statistics and Analysis, NHTSA. U.S. Department of Transportation., 2020.

7. Michigan Traffic Crash Facts. https://www.michigantrafficcrashfacts.org/. Accessed Jun. 30, 2019.

8. American Association of State Highway and Transportation Officials, Ed. A Policy on Geometric Design of Highways and Streets. American Association of State Highway and Transportation Officials, Washington, D.C, 2001.

9. AASHTO. https://www.transportation.org/. Accessed Apr. 5, 2020.

10. Harwood, D. W., F. M. Council, E. Hauer, W. E. Hughes, and A. Vogt. Prediction of the Expected Safety Performance of Rural Two-Lane Highways. Publication FHWA-RD-99-207. Federal Highway Administration, U.S. Department of Transportation, 2000.

11. Vogt, A., and J. Bared. Accident Models for Two-Lane Rural Segments and Intersections. Transportation Research Record: Journal of the Transportation Research Board, Vol. 1635, No. 1, 1998, pp. 18-29. https://doi.org/10.3141/1635-03.

12. Highway Safety Manual. American Association of State Highway and Transportation Officials, 2010.

13. Dixon, K., M. Chris, X. Fei, and G. Kristie. Calibrating the Future Highway Safety Manual Predictive Methods for Oregon State Highways. Publication FHWA-OR-RD-12-07. Oregon Department of Transportation and Federal Highway Administration, 2012.

14. Stapleton, S. Y., A. J. Ingle, M. Chakraborty, T. J. Gates, and P. T. Savolainen. Safety Performance Functions for Rural Two-Lane County Road Segments. Transportation Research Record: Journal of the Transportation Research Board, Vol. 2672, No. 52, 2018, pp. 226237. https://doi.org/10.1177/0361198118799035.

15. McLean, J. Practical Relationships for the Assessment of Road Feature Treatments - Summary Report. ARRB Group Ltd., 1997.

16. Taylor, M. C., D. A. Lynam, and A. Baruya. The Effects of Drivers' Speed on the Frequency of Road Accidents. Crowthorne: Transport Research Laboratory, 2000.

17. Fieldwick, R., and R. J. Brown. The Effect of Speed Limits on Road Casualties. Traffic Engineering \& Control, Vol. 28, No. 12, 1987, pp. 635-640.

18. Savolainen, P. T., T. Gates, D. Lord, S. Geedipally, E. Rista, T. Barrette, P. Thompson, and I. Thompson. Michigan Urban Trunkline Segments Safety Performance Functions (SPFs) 
Chakraborty and Gates

Development and Support. Publication RC-1639. Michigan Department of Transportation, 2016.

19. Hauer, E., F. M. Council, and Y. Mohammedshah. Safety Models for Urban Four-Lane Undivided Road Segments. Transportation Research Record: Journal of the Transportation Research Board, Vol. 1897, No. 1, 2004, pp. 96-105. https://doi.org/10.3141/1897-13.

20. Harwood, D. W., K. M. Bauer, K. R. Richard, D. K. Gilmore, J. L. Graham, L. B. Potts, D. J. Torbic, and E. Hauer. Methodology to Predict the Safety Performance of Urban and Suburban Arterials. Transportation Research Record: Journal of the Transportation Research Board, 2007. https://doi.org/10.17226/23084.

21. Dixon, K., A. Raul, B. Lacy, M. Megan, and S. Ida van. Quantifying Safety Performance of Driveways on State Highways. Publication FHWA-OR-RD-13-02. Oregon Department of Transportation and Federal Highway Administration, 2012.

22. Chakraborty, M., and T. J. Gates. Association between Driveway Land-Use Type and Safety Performance on Rural Highways. Transportation Research Record: Journal of the Transportation Research Board, Vol. In revision, 2020.

23. Papayannoulis, V., J. S. Gluck, K. Feeney, and H. S. Levinson. Access Spacing and Traffic Safety. Urban Street Symposium, 1999, pp. 28-30.

24. Potts, I. B., D. W. Harwood, and K. R. Richard. Relationship of Lane Width to Safety for Urban and Suburban Arterials. Transportation Research Record: Journal of the Transportation Research Board, Vol. 2023, No. 1, 2007, pp. 63-82.

25. Hadi, M. A., J. Aruldhas, L. F. Chow, and J. A. Wattleworth. Estimating Safety Effects of Cross-Section Design for Various Highway Types Using Negative Binomial Regression. Transportation Research Record: Journal of the Transportation Research Board, Vol. 1500, No. $169,1995$.

26. Heimbach, C. L., P. D. Cribbins, and M. S. Chang. Some Partial Consequences of Reduced Traffic Lane Widths on Urban Arterials. Transportation Research Record: Journal of the Transportation Research Board, Vol. No. HS-037 060, 1983.

27. Milton, J., and F. Mannering. The Relationship among Highway Geometrics, Traffic-Related Elements and Motor-Vehicle Accident Frequencies. p. 19.

28. Bonneson, J., M. Pratt, J. Miles, and P. Carlson. Horizontal Curve Signing Handbook. Publication FHWA/TX-07/0-5439-P1. Texas Department of Transportation, 2007.

29. Chakraborty, M., and T. J. Gates. Relationship between Horizontal Curve Density and Safety Performance on Rural Two-Lane Road Segments by Road Jurisdiction and Surface Type. Presented at the TRB Annual Meeting, 2021, Washington, D.C, 2021.

30. Hummer, J. E., W. Rasdorf, D. J. Findley, C. V. Zegeer, and C. A. Sundstrom. Curve Collisions: Road and Collision Characteristics and Countermeasures. Journal of Transportation Safety \& Security, Vol. 2, No. 3, 2010, pp. 203-220. https://doi.org/10.1080/19439961003734880.

31. Barua, S., K. El-Basyouny, and M. T. Islam. Factors Influencing the Safety of Urban Residential Collector Roads. Journal of Transportation Safety \& Security, Vol. 8, No. 3, 2016, pp. 230-246. https://doi.org/10.1080/19439962.2015.1025459.

32. Banihashemi, M. Effect of Horizontal Curves on Urban Arterial Crashes. Accident Analysis \& Prevention, Vol. 95, 2016, pp. 20-26. https://doi.org/10.1016/j.aap.2016.06.014.

33. Fitzpatrick, K. Design Speed, Operating Speed, and Posted Speed Practices. Publication NCHRP Report 504. Transportation Research Board: National Research Council, 2003.

34. Greibe, P. Accident Prediction Models for Urban Roads. Accident Analysis and Prevention, Vol. 35, No. 2, 2003, pp. 273-285. https://doi.org/10.1016/s0001-4575(02)00005-2. 
Chakraborty and Gates

35. Zegeer, C. V., J. Richard Stewart, H. Huang, and P. Lagerwey. Safety Effects of Marked Versus Unmarked Crosswalks at Uncontrolled Locations: Analysis of Pedestrian Crashes in 30 Cities. Transportation Research Record: Journal of the Transportation Research Board, Vol. 1773, No. 1, 2001, pp. 56-68. https://doi.org/10.3141/1773-07.

36. Bureau, U. C. Census.Gov. https://www.census.gov/en.html. Accessed Jun. 13, 2019.

37. State of Michigan. https://gis-michigan.opendata.arcgis.com/. Accessed Apr. 23, 2019.

38. HPMS Public Release of Geospatial Data in Shapefile Format - Policy | Federal Highway Administration. https://www.fhwa.dot.gov/policyinformation/hpms/shapefiles.cfm. Accessed May 1, 2019.

39. Data and Maps. Southeast Michigan Council of Governments. https://semcog.org/data-andmaps. Accessed Apr. 23, 2019.

40. Hauer, E., C. N. N. Jerry, and J. Lovell. Estimation of Safety at Signalized Intersections. Transportation Research Record: Journal of the Transportation Research Board, Vol. 1185, 1988, pp. 48-61.

41. Persaud, B., and L. Dzbik. Accident Prediction Models for Freeways. Transportation Research Record: Journal of the Transportation Research Board, Vol. 1401, 1993, pp. 55-60.

42. Oh, J., C. Lyon, S. Washington, B. Persaud, and J. Bared. Validation of FHWA Crash Models for Rural Intersections: Lessons Learned. Transportation Research Record: Journal of the Transportation Research Board, Vol. 1840, No. 1, 2003, pp. 41-49. https://doi.org/10.3141/1840-05.

43. Anastasopoulos, P. C., and F. L. Mannering. A Note on Modeling Vehicle Accident Frequencies with Random-Parameters Count Models. Accident Analysis \& Prevention, Vol. 41, No. 1, 2009, pp. 153-159. https://doi.org/10.1016/j.aap.2008.10.005.

44. Shankar, V. N., R. B. Albin, J. C. Milton, and F. L. Mannering. Evaluating Median Crossover Likelihoods with Clustered Accident Counts: An Empirical Inquiry Using the Random Effects Negative Binomial Model. Transportation Research Record: Journal of the Transportation Research Board, Vol. 1635, No. 1, 1998, pp. 44-48. https://doi.org/10.3141/1635-06.

45. Mannering, F. L., V. Shankar, and C. R. Bhat. Unobserved Heterogeneity and the Statistical Analysis of Highway Accident Data. Analytic Methods in Accident Research, Vol. 11, 2016, pp. 1-16. https://doi.org/10.1016/j.amar.2016.04.001.

46. Chakraborty, M., S. Y. Stapleton, M. Ghamami, and T. J. Gates. Safety Effectiveness of AllElectronic Toll Collection Systems. Advances in Transportation Studies, Vol. 2, No. Special Issue, 2020, pp. 127-142.

47. Abdel-Aty, M. A., and A. E. Radwan. Modeling Traffic Accident Occurrence and Involvement. Accident Analysis \& Prevention, Vol. 32, No. 5, 2000, pp. 633-642. https://doi.org/10.1016/S0001-4575(99)00094-9. 